\title{
La concepción de la pena en el magisterio actual
}

\author{
GUSTAVO IRRAZÁBAL \\ Pontificia Universidad Católica Argentina \\ girrazabal@gmail.com
}

\begin{abstract}
Resumen
La teología católica de la pena, que durante siglos se mantuvo prácticamente inalterada, ha experimentado en los últimos 20 años una profunda transformación, impulsada por la idea conciliar de la dignidad de la persona humana, una más cabal comprensión del concepto bíblico de justicia divina y una conciencia más aguda de las deficiencias e injusticias del sistema penal, en particular, de la pena carcelaria. El presente artículo, a través del estudio de diversos documentos magisteriales relevantes para este tema, ilustra la nueva perspectiva de la justicia reconciliadora, que busca dar a la sanción retributiva un sentido auténticamente medicinal, convirtiéndola en un recorrido potencialmente dotado de sentido para el delincuente, conducente a su rehabilitación y su reinserción en la comunidad.

Palabras claves: Pena, retribución, justicia divina, justicia reconciliadora, prisión.
\end{abstract}

\section{The conception of punishment in the current Magisterium}

\begin{abstract}
The Catholic Theology of punishment, which for centuries had remained unaltered, has undergone during the last 20 years a deep transformation, due to the conciliar idea of the dignity of the buman person, a better understanding of the biblical concept of divine justice, and a new awareness of the deficiencies of the criminal justice system, especially as regards prison. This article, through the analysis of different magisterial documents, illustrates the new perspective of reconciliative justice, which seeks to give retributive sanctions an authentic medicinal orientation, as a potentially meaningful process for their subjects, in order to enable their rehabilitation and reintegration in the community.
\end{abstract}

Key words: Punishment, retribution, divine justice, reconciliative justice, prison.

Sacerdote por la Arquidiócesis de Buenos Aires. Cursó estudios de licenciatura y doctorado en teología moral en la Pontificia Universidad Gregoriana de Roma. Profesor de teología moral en la Facultad de Teología y otras unidades académicas de la UCA, en los cursos de Moral fundamental, Doctrina Social de la Iglesia, Moral sexual y Moral socio-política. Entre sus publicaciones destacan los libros Doctrina Social de la Iglesia y ética politica (2009) y El camino de la comunión. Introducción a la moral fundamental (2010). 
La concepción de la pena, del derecho penal y la justicia penal han entrado en el siglo pasado en una profunda crisis (D'Agostino, 1992: 994-995). La idea de retribución ha sido intensamente criticada como violenta y estéril, dando lugar en las últimas décadas a propuestas de justicia «restitutiva» focalizadas en reparar el daño producido por el delito, y en articular procedimientos que involucren al delincuente activamente en ese propósito, favoreciendo así su rehabilitación, y la atención de los reales intereses de las víctimas (Highton, Álvarez \& Gregorio, 1998: 71-92). Los límites de la cárcel como modalidad de sanción penal hoy están a la vista, y surgen numerosas propuestas de sanciones alternativas con efectos más constructivos para los afectados y para la sociedad (lo cual, como veremos, hasta ahora no le ha hecho perder a la pena carcelaria su dramática centralidad como instrumento sancionatorio) (Eusebi, 2007b).

Pero la crisis no se ha detenido en el problema de los fines y modalidades de la pena, sino que ha alcanzado la pena como tal, en su fundamento jurídico y moral. En particular, las teorías jurídico-penales llamadas genéricamente «críticas» tienden a presentar la pena como una mera función de dinámicas macro-sociales, más precisamente, como instrumento de opresión a los sectores más débiles en manos de las clases favorecidas (Yacobucci, 2000). Se han puesto en evidencia como nunca antes los mecanismos de la justicia penal que son funcionales a estas situaciones de injusticia estructural (basta pensar en la «selectividad» evidente del sistema penal, que se concentra arbitrariamente en ciertos estratos, los más vulnerables, de la sociedad).

Correlativamente, se ha llegado a cuestionar no sólo el modo en que el Estado ejerce el ius puniendi sino la existencia de tal potestad, atribuyéndola a una determinada figura histórica (una verdadera "expropiación" del delito por parte de la autoridad pública, en perjuicio de la víctima), que hoy debe ser superada, llegando a proponerse tanto por razones de principio como de eficiencia, la sustitución del actual sistema penal público por soluciones a nivel local-comunitario, de modo parcial («minimalismo») o total («abolicionismo») (Zaffaroni, 1989: 99117).

Frente a este interesante, e incluso agitado, panorama, el magisterio sobre la pena en el mismo período se mantuvo sustancialmente intacto, repitiendo rutinariamente la doctrina tenida por «tradicional» (debemos constatar todavía si lo es realmente), anclada en una idea de retribución más bien filosófica, de escasa inspiración bíblica y evangélica, y abstraída de las condiciones concretas en que las penas se aplican, especialmente, el marco jurídico-político de dicha aplicación. 
Por razones a las que haremos referencia, la situación comenzó a cambiar en los años ' 90 del siglo pasado, y lo hizo con un dinamismo inusitado, cuyos avances y retrocesos muestran no sólo la complejidad del proceso, sino la vitalidad con que el mismo se desarrolla ante nuestros ojos, abrevando en una nueva comprensión de la Tradición. Ello hace de la teología de la pena y de la reflexión teológica sobre la cuestión penal uno de los ámbitos más prometedores de la reflexión social católica.

Este artículo procurará esbozar las líneas generales de esta evolución. Comenzaremos por mostrar un panorama del término a quo de este recorrido, la pena en el magisterio de Pío XII. A continuación, luego de mencionar algunos factores que movilizaron la revisión crítica de ese discurso, vamos a detenernos en algunos textos importantes: el Catecismo de la Iglesia Católica en su primera edición, de 1992 (en adelante, CEC1), la encíclica de Juan Pablo II, Evangelium vitae, de 1995 (en adelante, EV), la revisión del Catecismo en la edición típica de 1997 (CEC2), y el Compendio de la Doctrina Social de la Iglesia de 2005 (CDS). Para permitir una mejor comprensión del avance notable que representa el CDS respecto a los textos precedentes, incluiremos también una referencia a algunas homilías y mensajes de Juan Pablo II sobre el tema. En las conclusiones señalaremos los logros, así como las posibilidades de progreso que se perfilan al cabo de este difícil pero fecundo camino.

\section{La pena en el magisterio de Pío XII}

Es un error frecuente atribuir a la Iglesia una concepción absoluta de la pena, según la cual el único fin posible, el que la justifica plenamente, es la retribución de la falta ${ }^{1}$. Es cierto que el magisterio tradicionalmente ha mantenido una concepción retributiva de la pena, considerándola como una sanción necesaria in se una vez que se ha violado el derecho positivo, a fin de que este último sea restablecido. Pero una vez logrado este propósito, y a diferencia de la teorías absolutas, integra otros fines, aunque no depende en modo absoluto de que los mismos se verifiquen de hecho (poena absoluta est ab effectu).

Pío XII se ocupa del tema para reafirmar enfáticamente, en línea con los teólogos católicos de su época, la doctrina retributiva, considerada esencial para el concepto de justicia:

Tal es la posición de E. Kant, cfr. Bondolfi, 1990: 270-273. 
Queda por decir una palabra sobre el sentido último de la pena. La mayor parte de las teorías modernas del derecho penal explican la pena y la justifican, en fin de cuentas, como una medida de protección, es decir, en defensa de la comunidad contra empresas delictuosas, y al mismo tiempo como un intento de traer al culpable a la observancia del derecho (...) Pero estas teorías se niegan a considerar como función capital de la pena la expiación del delito, al cual sanciona el derecho violado (...) La esencia de la falta consiste en la oposición libre a la ley reconocida como obligatoria, en la ruptura y la violación consciente y querida del orden justo. Una vez que se ha producido es imposible lograr que ella no exista. Pero, no obstante, en cuanto se pueda dar satisfacción al orden violado, hay que dársela. Lo exige fundamentalmente la justicia. Su función en el dominio de la moralidad consiste en mantener la igualdad comprometida. Esta pide que, por la pena, el responsable sea sometido forzosamente al orden. El cumplimiento de esta exigencia proclama la supremacía absoluta del bien sobre el mal; por su medio se ejercita la soberanía absoluta del derecho sobre la injusticia (...) En esta última acepción de la pena, se ve también plenamente revalorizada la función de protección, que le atribuyen los modernos pero aquí se la expone más a fondo. Se trata, en efecto, ante todo, no de proteger los bienes asegurados por el derecho, sino el derecho mismo (...) Afirmamos, entonces, que no sería justo rechazar por principio y en forma total la función de la pena vindicativa (...) es de mayor conformidad con lo que las fuentes de la Revelación y de la doctrina tradicional enseñan sobre el poder coercitivo de la autoridad (Pío XII, 1953: n. 4).

Como se ve con claridad, la perspectiva adoptada es de carácter jurídico-metafísico: la pena es una exigencia incondicionada de que el orden trascendente de la justicia sea reparado (Thiefry, 1961). Pero esta posición tradicional es formulada en términos polémicos contra las teorías de corte sociológico que, negando la idea misma de culpa, ponen en peligro la lógica estrictamente jurídica de la retribución (la pena debe corresponder a una culpa y ser proporcionada a su gravedad), llevando a una indiscriminada «medicalización» del fenómeno criminal (Lattuada, 1998: 183) $)^{2}$.

Sin embargo, no separa la retribución del efecto medicinal, consistente en la redención del culpable a través de la pena:

La pena propiamente dicha, no puede, pues, tener otro sentido y finalidad que los que acabamos de indicar, a saber, de volver de nuevo al violador del derecho a los carriles del deber que había abandonado (...) A su modo,

\footnotetext{
2 Véase también las reflexiones de M. Foucault (2002: 23-31) sobre el «modelo disciplinario» adoptado por los sistemas penales occidentales en los últimos 200 años.
} 
la pena cumple su oficio, en cuanto obliga al culpable por causa del acto cometido, a un sufrimiento, es decir, a la privación de un bien y a la imposición de un mal. (...) Mientras el hombre vive sobre la tierra, ésa (la pena) también puede y debe servir a su definitiva salvación, siempre que él mismo no ponga, por otra parte, obstáculo a la eficacia saludable de tal pena. Tal eficacia no se opone efectivamente de modo alguno a la función de equilibrio y de reintegración del orden turbado, que ya hemos indicado como esencial a la pena (Pío XII, 1955).

En esta tensión entre el fin retributivo y el medicinal, Pío XII sigue a Santo Tomás, según el cual la pena puede ser considerada desde un doble punto de vista: como castigo $^{3}$ (destinado a la restauración de la justicia, compensando la ventaja injusta obtenida por el delincuente con un daño contra su voluntad), pero también como medicina, ya que el mundo presente no es el lugar de la definitiva restauración de la justicia ${ }^{4}$.

Es cierto que la idea retributiva de la pena apunta a un objetivo de justicia irrenunciable, el de privar al delincuente de la ventaja injustamente obtenida. Pero con referencia a la culpa moral que conlleva el delito, esta perspectiva es reductiva. Como observa agudamente A. Lattuada, esta visión se funda en una supuesta correspondencia simétrica entre la fractura del orden ético-jurídico de un lado, y la composición del mismo a través de la pena, del otro. Pero ambas realidades se sitúan en planos absolutamente distintos: la primera, en el interior de la libertad moral; la segunda, en el orden exterior de la coacción física. Por eso la pena no puede remediar el desorden introducido por el delito. "La acción moralmente mala sólo puede ser eventualmente remediada por una acción de signo opuesto, pero de todos modos, de naturaleza moral, o sea, voluntaria y libremente realizada» (Lattuada, 1998: 183). Esta afirmación relativiza fuertemente la idea de retribución y señala la dirección para una superación del reduccionismo legalista. Sin embargo, seguir esa línea de reflexión exigirá recorrer un largo y sinuoso camino.

\footnotetext{
3 «En este sentido, sólo el pecado merece la pena, porque por ella se restaura la igualdad de la justicia en cuanto causa al pecador un daño contra su voluntad, como antes en el pecado se excedió en seguir su propia voluntad. Por lo cual, como todo pecado es voluntario, incluso el original, síguese que nadie es castigado con tal género de pena sino por el pecado voluntario», Summa Theologiae, II-II, q.108, a.4c.

4 «Las penas en la vida presente no son queridas por sí mismas, porque no es aquí el momento de la sanción final: ellas, en cambio, son buscadas como penas medicinales, que miran a la enmienda del culpable o al bien de la sociedad, cuya tranquilidad es asegurada por la punición del delincuente», Summa Theologiae, II-II, q.68, a.1.
} 


\section{Razones de un cambio}

Antes de focalizarnos en la evolución del magisterio a partir del CEC, conviene señalar algunos factores que han impulsado la revisión de la enseñanza «tradicional».

\section{a) La renovada reflexión bíblica}

La orientación retributivista del discurso clásico sobre la pena (incluso acentuada en la época moderna, en desmedro de la finalidad medicinal) adolecía de una muy escasa fundamentación bíblica. Sorprendentemente, la imagen de Jesús condenado injustamente a muerte, o su identificación con todos los encarcelados, culpables o no, («estuve preso y me visitasteis», Mt 25,36), parecía no tener ya lugar alguno en la reflexión sobre el tema (aunque sí lo había tenido en otras épocas de la historia) (Skotnicki, 2008: 17-25). Tal impostación de fondo, sin embargo, comienza a cambiar cuando se introduce en este ámbito una nueva concepción de la justicia divina aportada por los estudios bíblicos ${ }^{5}$.

En efecto, la idea bíblica de justicia (tsedāqāh) define, en primer lugar, la actitud de Dios que da el primer paso hacia el hombre pecador ofreciéndole la posibilidad de la conversión y la reconciliación. Se trata, por lo tanto, de una justicia que es, al mismo tiempo y por eso mismo, misericordia (Eusebi, 1998: 220). Sólo cuando esta comprensión bíblica de la justicia fue traducida a la cultura greco-latina con los conceptos de

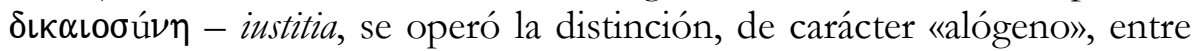
justicia (exclusivamente retributiva) y misericordia (que «atempera» la justicia así entendida) (Wiesnet, 1987: 78). De ahí la necesidad de recuperar, en perspectiva histórico salvífica, esa referencia de ambas al amor gratuito, misericordioso y santificante de Dios.

En continuidad con lo dicho, es claro también que la pena en la Biblia no es algo que se agrega a la culpa desde fuera, sino más bien la consecuencia inmanente del mal cometido y del desorden que el mismo introduce en el mundo y en el corazón humano, cuyo despliegue Dios permite en su providencia, con vistas a la salvación y la reconciliación (Koch, 1972: 166). El pecado es siempre, a la vez que obra de la libertad humana, un auto-engaño. La punición, poniendo en evidencia el mal, devuelve al culpable a la realidad de su situación y, por la aceptación humilde de esa realidad, lo introduce en el camino de la conversión.

\footnotetext{
5 Sigo en este punto a Fabris, 2003: 195-199; véase también León-Dufour, 1985: 465-466.
} 
Es claro que este concepto de la justicia divina no puede aplicarse al ámbito jurídico en modo directo, sin tener en cuenta adecuadamente las mediaciones humanas, pero sin duda debe ocupar un lugar central en la reflexión teológica sobre el tema (Lattuada, 1998: 188-189), y constituye un criterio de juicio insoslayable sobre las ideas y la praxis penal.

\section{b) La dignidad de la persona bumana}

Junto con una renovada inspiración bíblica, se verifica un creciente y sistemático recurso a la dignidad y los derechos del hombre, sobre todo a la luz del tema bíblico-teológico del hombre como imagen de Dios, que impulsa la progresiva transformación de ciertos conceptos y ciertas perspectivas hermenéuticas. El giro hacia la persona, no sólo como concepto metafísico sino en su ser concreto y biográfico, que se verificó en el Vaticano II, de un modo particular con Gaudium et spes y Dignitatis humanae, comienza ahora a ser aplicado con una nueva consistencia a la materia penal, como perspectiva central y articuladora de todos los aspectos del problema (Carlotti, 2007: 46-47).

La consecuencia más importante de esta nueva sensibilidad, es la afirmación de la dignidad humana no sólo de la víctima, sino del mismo delincuente. Declara enfáticamente EV 9 en referencia a Caín y la señal que Dios imprime en su frente: «Ni siquiera el homicida pierde su dignidad personal y Dios mismo se hace su garante» (subrayado del texto). Y con referencia a la pena de muerte, afirma: «El problema se enmarca en la óptica de una justicia penal que sea cada vez más conforme con la dignidad del hombre y por tanto, en último término, con el designio de Dios sobre el hombre y la sociedad» (EV 55).

\section{c) El marco ético-político}

La enseñanza de la Iglesia sobre el tema de la pena adoleció hasta tiempos recientes de una cierta ingenuidad, al no tomar suficientemente en consideración la problematicidad inherente al poder político. Más aún, en la Época Moderna, por influencia de la filosofía nominalista, la idea de justicia tendió a identificarse con el orden social existente, con lo cual la teología perdió progresivamente su capacidad crítica de la realidad social (Bondolfi, 1990: 282-283).

Por ello en la tradición católica, hasta tiempos recientes, no se ha prestado suficiente atención a la relación de la pena con la ética política: aquella era considerada como un problema sectorial y no como una cuestión relacionada íntimamente con la legitimidad y los límites del poder estatal. Era necesario, por consiguiente, superar el carácter 
abstracto de la doctrina precedente, y adoptar una perspectiva más crítica, libre de incrustaciones ideológicas, en mayor contacto con los problemas sociales reales, y en estrecho diálogo con las ciencias humanas.

De este modo, la teología católica actual asume la misión de orientar una praxis humanizadora. «El criterio para juzgar desde el punto de vista ético-teológico las doctrinas e instituciones penales no puede ser otro que su capacidad histórica de limitar la ideología de la venganza y la omnipotencia del Estado, y de responder a las exigencias de la dignidad de la persona humana» (Bondolfi, 1990: 285).

\section{d) La crítica al sistema penal y a la política penitenciaria}

Finalmente, un factor apremiante surge de la evidente y creciente disfuncionalidad del sistema penal en muchos países. Por citar sólo un ejemplo, el 15 de noviembre de 2000, la Conferencia Episcopal de los Estados Unidos, publicó el documento «Responsabilidad, rehabilitación, y restauración», donde por primera vez abordó de modo sistemático, a la luz de la fe católica y apoyándose en una amplia consulta, el problema de la justicia penal en ese país ${ }^{6}$.

Aunque los obispos americanos reconocen que, a partir de 1991, se ha verificado una caída constante de los índices de criminalidad luego de treinta años de significativo crecimiento, llaman la atención sobre la insuficiencia de esa estadística para juzgar las políticas criminales empleadas. En USA el porcentaje de encarcelamiento es elevadísimo: para la época de la redacción del documento, ascendía a 668 por cada 100.000 ofensores, 6 a 12 veces más que en los restantes países occidentales ${ }^{7}$. Esta política centrada en la pena de prisión, se lleva adelante con enormes costos económicos, a expensas de programas de tratamiento (sobre todo de adicciones), mientras simultáneamente se

\footnotetext{
6 Conferencia de los Obispos Católicos de los Estados Unidos, 1990. Para otra aguda crítica a la política penal de los Estados Unidos, aplicando los principios de la guerra justa, McCormick, 2000.

Según datos más recientes, la cifra sería de 756 presos cada 100.000 habs. (en Francia el porcentaje es 91/100.000; en Argentina, 134/100.000). En cuanto a la población carcelaria, si en 1972, la misma ascendía a 250.000, en el 2000, el número creció hasta los 2.000.000 (actualmente supera los 2.259.000 personas, constituyendo 1/4 de la población carcelaria mundial, a lo que se debe agregar 7.000.000 de adultos bajo supervisión correccional). La composición de dicha población es también sugestiva: los afroamericanos, que representan el 12\% de la población del país, constituyen el $49 \%$ de la población carcelaria. Uno cada diez afroamericanos está en prisión. Los hispanoamericanos (9\% de la población) constituyen el 19\% del total de internos en las cárceles federales y estaduales.
} 
reduce el presupuesto de servicios como educación, salud, transporte, etc., lo que plantea graves problemas de justicia distributiva.

Este diagnóstico pone de manifiesto un problema que afecta a la mayoría de los países: un sistema penal basado fundamentalmente en la retribución y la cárcel no parece sustentable económica y socialmente, y se vacía progresivamente de legitimidad. El recurso a la neutralización detentiva en vastísima escala no resuelve los problemas sociales, sino que más bien los exaspera y difiere su explosión, mientras genera problemas aun más graves para la democracia y los derechos humanos. La legitimidad del sistema penal depende de su capacidad para favorecer la asunción de responsabilidades, la restauración de los vínculos sociales afectados y la rehabilitación del delincuente.

En el contexto que surge de los factores precedentemente mencionados, debe situarse el camino del magisterio católico, y la vitalidad que adquirió la reflexión eclesial sobre este tema en los últimos 20 años.

\section{La pena en el CEC1 (1992)}

El Catecismo de la Iglesia Católica, publicado el 11 de octubre de 1992, trata el tema de la pena en la parte III («La vida en Cristo»), artículo 5 («El quinto mandamiento»), bajo el título «Respeto de la vida humana». La afirmación del valor de la vida humana funda la grave inmoralidad del homicidio voluntario (n. 2261). Pero ello no obsta a la licitud de la «legítima defensa», es decir, la situación en que la muerte del agresor es efecto no querido de la acción de preservar la propia vida (n. 2263). Esta reacción a la violencia ajena puede constituir un deber para el responsable de la vida de otro, del bien común de la familia o de la sociedad (n. 2265).

En este punto, se vincula el tema de la pena al concepto de legítima defensa social (n. 2266):

La preservación del bien común de la sociedad exige colocar al agresor en estado de no poder causar perjuicio. Por este motivo la enseñanza tradicional de la Iglesia ha reconocido el justo fundamento del derecho y deber de la legítima autoridad pública para aplicar penas proporcionadas a la gravedad del delito, sin excluir en casos de extrema gravedad, el recurso a la pena de muerte. La pena tiene, ante todo, la finalidad de reparar el desorden introducido por la culpa. Cuando la pena es aceptada voluntariamente por el culpable, adquiere un valor de expiación. La pena 
finalmente, además de la defensa del orden público y la tutela de la seguridad de las personas, tiene una finalidad medicinal: en la medida de lo posible, debe contribuir a la enmienda del culpable.

La ubicación sistemática de este texto, a la cual acabamos de hacer referencia, es muy sugestiva, y explica bien el sesgo de su contenido. La dignidad de la vida humana es considerada en la perspectiva binaria que contrapone inocentes y culpables y se aplica específicamente al homicidio. Se opta así por un enfoque que restringe fuertemente el campo de la sanción penal, que de este modo es considerada a partir del delito de mayor gravedad, preparando así la argumentación sobre la pena de muerte. Al mismo tiempo, el tratamiento del tema se focaliza exclusivamente en la dignidad de la vida inocente (n. 2258), es decir, de la víctima, y la condena del obrar del homicida (n. 2261). Esto se ilustra con el relato de la acción fratricida de Caín contra Abel y la consiguiente maldición divina (n. 2259), y con la advertencia de Yahvé de que quien vierta sangre de hombre pagará con su propia sangre (cf. Gen 9,5-6; n. 2260).

Luego (n. 2262) se insinúa una relativización de esta lógica retributiva citando el mandato del Señor a sus discípulos de poner la otra mejilla (Mt 5,39) y de amar a sus enemigos (v.44). Esta referencia al Sermón de la Montaña presenta, en efecto, la oportunidad de ampliar el horizonte de la reflexión introduciendo la consideración de la dignidad humana del culpable, y la responsabilidad de la sociedad respecto de él. Pero este número queda encapsulado como una mera interpolación, e inmediatamente se retoma la perspectiva excluyente de la víctima (las personas y las sociedades) afirmando su derecho a legítima defensa frente al agresor, aunque ello conlleve, como consecuencia no querida, la muerte de éste (nn. 2263-2264).

En este marco de referencia, CEC ubica el tema de la potestad punitiva como derecho y deber del Estado. El segundo párrafo del $\mathrm{n}$. 2266 elenca en el siguiente orden los fines de la pena:

1. El «primer efecto» es el de «compensar el desorden introducido por la falta». El término «desorden» tiene aquí un sentido ético-jurídico: la justicia exige que la falta sea compensada por una sanción proporcional, de modo que la voluntad rebelde sea retrotraída a su justo límite. Es lo que se denomina el sentido retributivo de la pena. Pero este procedimiento, que tiene lugar en el fuero externo, no repercute automáticamente en el plano ético-personal. En el caso en que alcance efectivamente la conciencia del culpable, y la pena sea aceptada voluntariamente por él, la misma alcanza un valor de expiación. 
2. En segundo lugar («además»), la pena tiene una función de defensa social, consistente en «preservar el orden público y la seguridad de las personas». Este criterio está subordinado al fin retributivo, probablemente para quedar encuadrado en una lógica específicamente jurídica evitando los excesos a que puede llevar la focalización en el concepto criminológico de «peligrosidad».

3. «Finalmente», la pena tiene un valor medicinal, «porque debe, en la medida de lo posible contribuir a la enmienda del culpable». Aparece aquí la única referencia bíblica en este tema: el «buen ladrón» (cf. Lc 23,40-43), notablemente, un ejemplo de enmienda no para esta vida sino exclusivamente para la vida eterna, porque su conversión tiene lugar en el momento de la muerte. Dado que en el Evangelio abundan los ejemplos de conversión como cambio de vida, la elección de este texto podría resultar francamente desconcertante, si no se tuviera en cuenta su carácter introductorio para el tema que sigue inmediatamente: el de la pena de muerte.

Desde una perspectiva personalista, llama la atención que el fin medicinal, el más directamente vinculado a la dignidad de la persona concreta del delincuente, ocupe sólo el tercer lugar en este elenco ${ }^{8}$, precedido por el fin externo-jurídico (retribución) y colectivo (defensa social). Además, estos fines están simplemente yuxtapuestos, sin una intrínseca conexión. ¿Es posible esperar del condenado una aceptación voluntaria de la pena (1) si ella no se revela desde sí como un camino idóneo para la superación de su delito (3)? ¿Es posible lograr una eficaz defensa social (2) por métodos predominantemente retributivos (1)? Y sobre todo, ¿se justifica una pena retributiva que no sea en sí misma, por su naturaleza, medicinal?

\section{CEC1 y pena de muerte}

Como vemos, el marco de referencia que se ha dado al tema (defensa de la vida inocente contra el agresor) produce un estrechamiento del horizonte que hace difícil trascender la lógica retributiva. Ya en el n. 2266 se afirma que el Estado tiene el deber de «aplicar penas proporcionadas a la gravedad del delito, sin excluir en casos de extrema gravedad, el recurso a la pena de muerte». Ciertamente la formulación es negativa y por lo tanto, restrictiva. De hecho, se

\footnotetext{
8 Como hemos dicho ya, Santo Tomás insistía en que las penas en este mundo son sobre todo medicinales, cf. Summa Theologiae, II-II, q.68, a.1.
} 
reserva para casos de «extrema gravedad». Ahora bien, ¿por qué motivo se habría de aplicar la pena de muerte a quien habiendo cometido un delito de extrema gravedad, ya no representa un peligro en acto para la sociedad? La perspectiva resulta más inquietante si recordamos el contexto de esta afirmación (el homicidio y la defensa de la vida), contexto en el cual la «extrema gravedad» deja de ser algo excepcional para formar parte del planteo.

De un modo más correcto, aunque inconsistente con la afirmación anterior, el n. 2267 aclara (más bien corrige) el párrafo precedente, señalando como única justificación de la pena de muerte, no la extrema gravedad del delito, sino la eventual insuficiencia de los medios incruentos para proteger el orden público y la seguridad de las personas. Para adoptar esta posición, el texto señala dos razones interesantes pero no desarrolladas: el bien común, y la dignidad de la persona humana (por primera y única vez, afirmada en referencia al delincuente).

No se puede concluir este primer análisis sin considerar más de cerca el argumento de la legítima defensa social (Eusebi, 1998: 244-245; Blázquez, 1996: 403-405). La legítima defensa sólo se considera tal cuando constituye la respuesta espontánea que busca detener o neutralizar una agresión en acto. No es el caso del condenado que, por definición, ha sido ya neutralizado por la fuerza pública. La utilización de este concepto como justificación de la pena y, en particular, de la pena de muerte es por lo tanto muy cuestionable. Además, debe tratarse de un ataque contra la vida, y no contra otros bienes jurídicos, con lo cual el concepto de legítima defensa social tampoco es apto para fundar la pena en general.

Por supuesto que siempre se puede responder que estamos ante una analogía entre la legítima defensa personal y la legítima defensa social. Pero el uso de analogías puede ser peligroso cuando se soslayan las diferencias que toda analogía entraña. En este caso, tal recurso puede ofuscar la percepción de que, desde el punto de vista de la defensa social, la imposición de penas tiene un carácter preventivo, es decir, que no consiste en repeler una agresión en acto sino en tutelar la comunidad frente a agresiones futuras.

\section{Pena en general y pena de muerte en EV}

La acentuación de la perspectiva personalista y la centralidad del tema de los derechos humanos en el magisterio de Juan Pablo II, así como su posición respecto de la pena de muerte, harían esperar un tratamiento sustancialmente distinto del tema de la pena en general. Sin 
embargo, EV 56 parece desmentir esta expectativa. De acuerdo a este texto:

En efecto, la pena que la sociedad impone «tiene como primer efecto el de compensar el desorden introducido por la falta» (CEC 2266). La autoridad pública debe reparar la violación de los derechos personales y sociales mediante la imposición al reo de una adecuada expiación del crimen, como condición para ser readmitido al ejercicio de la propia libertad. De este modo la autoridad alcanza también el objetivo de preservar el orden público y la seguridad de las personas, no sin ofrecer al mismo reo un estímulo y una ayuda para corregirse y enmendarse (EV 56).

A simple vista puede advertirse una acentuación de la perspectiva retributiva. La expiación ya no se refiere a la aceptación voluntaria de la pena, sino al correlato objetivo de la sanción, el padecimiento de la pena por parte del reo. La verificación de estos fines (retribución- expiación) a través de la imposición de la pena parece constituir por sí misma la garantía del orden y seguridad públicos, y la condición suficiente para favorecer la enmienda.

El párrafo citado, sin embargo, no parece consistente con la inspiración de fondo del documento (Lattuada, 1998: 179-181). Por lo pronto, no es posible pasar por alto el contraste entre el recurso al relato del crimen de Caín en el CEC1 y en EV. Mientras que en el primero se recurre a dicho relato con el fin exclusivo de afirmar la gravedad del homicidio y la justicia de la retribución correspondiente, siempre en la perspectiva de la víctima (Abel) y contra el agresor, EV introduce una novedad. Luego de reafirmar que «Dios no puede dejar impune el delito» (9.1), agrega recordando la señal que Dios pone a Caín para protegerlo, que ni siquiera el homicida pierde su dignidad personal y Dios mismo se hace su garante, y refiere explícitamente esta afirmación al misterio de la misericordia de Dios (9.3)

Este, y no el principio retributivo afirmado vigorosamente en el $\mathrm{n}$. 56, parece constituir el verdadero marco de referencia en que la encíclica coloca el problema de la pena de muerte. Una prueba de ello es la valoración positiva del rechazo creciente en la opinión pública de la violencia como método de resolución de conflictos, refiriéndolo a la guerra como modo de combatir la agresión armada, y a la pena capital como instrumento para procurar la defensa social (n. 27.3).

Es evidente que, precisamente para conseguir todas estas finalidades, la medida y la calidad de la pena deben ser valoradas y decididas atentamente, sin que se deba llegar a la medida extrema de la eliminación del reo salvo en casos de absoluta necesidad, es decir, cuando la defensa de la sociedad no 
sea posible de otro modo. Hoy, sin embargo, gracias a la organización cada vez más adecuada de la institución penal, estos casos son ya muy raros, por no decir prácticamente inexistentes.

De todos modos, permanece válido el principio indicado por el nuevo Catecismo de la Iglesia Católica, según el cual «si los medios incruentos bastan para defender las vidas humanas contra el agresor y para proteger de él el orden público y la seguridad de las personas, en tal caso la autoridad se limitará a emplear sólo esos medios, porque ellos corresponden mejor a las condiciones concretas del bien común y son más conformes con la dignidad de la persona humana» (CEC 2267).

Se señala aquí un elemento que esclarece en parte el n. 56, y pone en evidencia también su no muy afortunada formulación. Para que la pena sea justa no basta que su medida sea cuantitativamente proporcional (lo cual, por otro lado, es stricto sensu imposible) sino que es necesario que su calidad, es decir, su contenido y las modalidades concretas de su aplicación, respondan a las exigencias del bien común y de la dignidad de la persona, haciéndola apta para cumplir sus funciones propias.

Dicho esto, y concentrándonos en la argumentación de los dos párrafos arriba citados, da la impresión de que debería invertirse su orden. El último de ellos, que repite el texto de CEC1 debería ocupar el primer lugar, dado que establece la condición para que la pena capital sea legítima: que los medios incruentos sean insuficientes para garantizar el orden y la seguridad públicos. El segundo, propio de EV, afirma que esa condición difícilmente se verifica porque tal situación es «prácticamente inexistente».

$\mathrm{El}$ paso que da $\mathrm{EV}$ ha sido interpretado por algunos autores sólo como un modo de negar la licitud de la pena de muerte en los hechos, afirmando al mismo tiempo su licitud en teoría como medida extrema?. La intención habría sido no desautorizar la enseñanza y la praxis de la Iglesia a lo largo de buena parte de su historia, presentando este giro del magisterio como el resultado de un cambio de situación (la existencia, en los Estados modernos, de sanciones alternativas suficientemente eficaces). Sin embargo, en un análisis hermenéutico más profundo, podría verse el texto de $\mathrm{EV}$ como una evolución, «en fase de compleción», hacia un rechazo de la pena de muerte como tal (Carlotti, 2007: 49).

Esto podría aclarar, a su vez, la correcta relación entre pena de muerte y legítima de defensa. En EV, a diferencia del CEC, la legítima

\footnotetext{
9 Blázquez (1996: 416), ve en la posición de EV sobre la pena de muerte una prolongación del «abolicionismo pastoral» del pasado, que es necesario superar con una condena incondicional de aquélla.
} 
defensa ya no es vista como la justificación de la pena capital (n. 27.3). Más bien, el respeto de la vida humana lleva a condenar la destrucción de la vida humana como pena, y a permitirla sólo como legítima defensa frente a una agresión en acto (Carlotti, 2007: 49) ${ }^{10}$.

\section{La pena en CEC2}

La edición típica del CEC (1997), sin alterar el cuadro de referencia del texto de 1992, introdujo algunas variantes de consideración. En primer lugar, en lo que se refiere a la pena en general, en nuevo texto del n. 2266 comienza del siguiente modo:

A la exigencia de la tutela del bien común corresponde el esfuerzo del Estado para contener la difusión de comportamientos lesivos de los derechos humanos y las normas fundamentales de la convivencia civil.

El nuevo texto precisa la referencia al bien común de la versión anterior: el ámbito del derecho penal debe ser restringido a la defensa de «los derechos humanos y las normas fundamentales de la convivencia civil». Se expresa aquí una visión de la intervención penal del Estado que los penalistas definirían como relativa, por estar referida a necesidades contingentes del bien común (Eusebi, 1998: 242).

La acción del Estado en este tema no se dirige directamente contra la persona del agresor, sino contra los comportamientos lesivos de los derechos básicos de las personas; y su fin no consiste sólo en neutralizar al primero (prevención especial) sino en evitar la difusión de dichos comportamientos (prevención general). Profundizar la idea de prevención como hace el nuevo texto permite esclarecer mejor que en CEC1 la idea de defensa social. Es también importante y potencialmente fecunda la introducción explícita del tema de los derechos humanos, aunque no se pone en relación con los fines de la pena, cuyo enunciado permanece intacto, con su sesgo netamente retributivo e inconsistente con la introducción de este número.

\section{CEC2 y la pena de muerte}

En relación con la pena de muerte, el tratamiento del tema pasa enteramente al n. 2267:

10 En contra, Blázquez (1996: 403-405), ateniéndose al tenor literal de los textos. 
La enseñanza tradicional de la Iglesia no excluye, supuesta la plena comprobación de la identidad y de la responsabilidad del culpable, el recurso a la pena de muerte, si esta fuera el único camino posible para defender eficazmente del agresor injusto las vidas humanas.

Pero si los medios incruentos bastan para proteger y defender del agresor la seguridad de las personas, la autoridad se limitará a esos medios, porque ellos corresponden mejor a las condiciones concretas del bien común y son más conformes con la dignidad de la persona humana.

Hoy, en efecto, como consecuencia de las posibilidades que tiene el Estado para reprimir eficazmente el crimen, haciendo inofensivo a aquél que lo ha cometido sin quitarle definitivamente la posibilidad de redimirse, los casos en los que sea absolutamente necesario suprimir al reo «suceden muy [...] rara vez [...], si es que ya en realidad se dan algunos» (EV 56).

La referencia a la «enseñanza tradicional» sobre la pena de muerte, como siempre, es de carácter restrictivo («no excluye»). Pero además cabría aclarar que la misma no pertenece en rigor a la Tradición apostólica, sino que constituye más bien una de las «tradiciones teológicas particulares» que como tales «pueden ser conservadas, modificadas o también abandonadas bajo la guía del magisterio de la

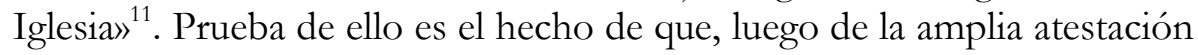
del AT, el NT guarda respecto de la pena de muerte un sustancial silencio, a la vez que genera una orientación de misericordia y clemencia que será constante a lo largo del período patrístico, incluso durante la época constantiniana (Blázquez, 1996: 411-414).

Más allá de esto, la referencia a «la plena comprobación de la identidad y de la responsabilidad del culpable», abre el camino a un tema hasta el momento no contemplado de modo explícito: el contexto político-institucional del ejercicio de la potestad penal y su funcionamiento concreto. De hecho, no puede escapar a la consideración del redactor que la dificultad para alcanzar esa «plena comprobación», y la imposibilidad de revertir un eventual error judicial, constituyen un fuerte argumento práctico contra la pena capital.

El CEC2, sin embargo, no se detiene en la explicitación de los presupuestos hermenéuticos de EV que hubieran permitido concluir en un rechazo de la pena de muerte como tal, y se limita a afirmar la imposibilidad práctica de que concurran las condiciones para su justificación.

11 Congregación para la Doctrina de la Fe, 1973: n.5. Cf. Carlotti, 2007: 41; Eusebi: 1998: 246-247; Blázquez, 1996: 417. 


\section{La pena y el jubileo en las cárceles (2000): la justicia y el perdón}

El tratamiento que hace Juan Pablo II del tema de la pena en Evangelium vitae es explicitado y profundizado con ocasión del Jubileo en las cárceles (9 de julio de 2000). En esta ocasión declara ante todo que, en orden a una reforma del sistema penal, los juristas están llamados a «reflexionar sobre el sentido de la pena y a abrir nuevas fronteras para la colectividad» (n. 5).

Un signo de la necesidad de reforma del sistema penal, surge de la evidencia de la insuficiencia de la pena de prisión como respuesta al delito: «Los datos que están a la vista de todos nos dicen que esta forma punitiva en general logra sólo en parte hacer frente al fenómeno de la delincuencia. Aún más, en muchos casos los problemas que crea son mayores que los que intenta resolver» (n. 5). Con esta crítica se introduce una nueva perspectiva: la del recurso a la pena de prisión en términos de rigurosa subsidiariedad, como extrema ratio, y de la promoción de penas alternativas.

La resocialización del delincuente es un objetivo irrenunciable de las sanciones penales. Los poderes públicos «deben saber que no son señores del tiempo del detenido» (n. 3), por lo cual «dejar de lado acciones promocionales (en relación a los presos) significaría reducir la medida de detención a mera retorsión social, haciéndola sencillamente odiosa» (n. 4). Como afirma en su homilía dirigida a los detenidos de la cárcel romana Regina Coeli, el mismo 9 de julio de 2000:

(...) la pena no puede reducirse a una simple dinámica retributiva; mucho menos puede transformarse en una retorsión social o en una especie de venganza institucional. La pena, la prisión tienen sentido si, mientras afirman la exigencia de la justicia y desalientan el crimen, sirven para la renovación del hombre, ofreciendo a quien se ha equivocado una posibilidad de reflexionar y cambiar de vida para reinsertarse plenamente en la sociedad (n. 5).

Esta finalidad no sólo no se contrapone a las exigencias de justicia, sino que se corresponde con el sentido no reductivo de la misma: «De vuestro camino no podrá sino alegrarse la sociedad entera. Las mismas personas a las cuales habéis causado dolor sentirán quizás que han logrado justicia más atendiendo a vuestro cambio interior que al simple precio pagado por vosotros» (n. 6). 
La concepción de la justicia subyacente a estas afirmaciones se vincula íntimamente con el concepto de perdón. Es lo que sostiene Juan Pablo II en el Mensaje para la Jornada mundial de la paz de 1997:

(...) la justicia no se limita a establecer aquello que es recto entre las partes en conflicto, sino que mira sobre todo a reconstituir relaciones auténticas con Dios, consigo mismo y con los otros. No subsiste, por lo tanto, ninguna contradicción entre perdón y justicia. El perdón, en efecto, no elimina ni disminuye la exigencia de la reparación, que es propia de la justicia, pero apunta a reintegrar sea las personas y los grupos en la sociedad, sea los Estados en la comunidad de las Naciones. Ningún castigo puede mortificar la inalienable dignidad de quien ha realizado el mal. La puerta hacia el arrepentimiento y la rehabilitación debe estar siempre abierta (n. 5, subrayado nuestro).

Esta idea es profundizada en el Mensaje del Papa para la Jornada Mundial de la paz de 2002:

El perdón va en contra del instinto espontáneo de retribuir el mal con el mal... En la medida en que se afirman una ética y una cultura del perdón, se puede esperar también una «politica del perdón» expresada en actitudes sociales e instituciones jurídicas en las cuales la misma justicia asuma un rostro más humano (n. 8, subrayado nuestro)

La mención de la dimensión política e institucional del perdón es de gran relevancia, porque supera la tendencia clásica a confinar el perdón en el ámbito privado y a ver en él una alternativa o renuncia a la justicia.

En esta óptica debe ser entendida la invitación del Papa en el Jubileo en las cárceles (9 de julio de 2000) a revisar de raíz las estrategias sancionadoras, abandonando la centralidad de la pena de prisión, en orden al «establecimiento de procesos de redención y de crecimiento personal y comunitario fundados en la responsabilidad». Tanto el pedido expresado en esa ocasión de un gesto de clemencia hacia los detenidos (reiterado el 14 de noviembre de 2002 ante el Parlamento italiano) como la firme postura adoptada en reiteradas ocasiones contra la ejecución de las condenas capitales, lejos de constituir episodios aislados revisten el carácter de verdaderos gestos proféticos.

El esfuerzo por la recuperación del delincuente y la reconciliación reparadora no constituye una mera concesión humanitaria en conflicto con los intereses de los ciudadanos, sino el factor cardinal de la estrategia de tutela de los bienes fundamentales: nada consolida más la autoridad del derecho que la elección personal del delincuente de tomar distancia 
de su conducta criminal e involucrarse en un proceso de justicia restitutiva a favor de las víctimas de su accionar (Eusebi, 2007b).

\section{La pena en el CDS}

Muchos de los progresos del magisterio en este tema quedan plasmados en el CDS. Más aun, el mismo constituye un nuevo paso adelante en cuanto a la sistematización y explicitación de dichos progresos.

En primer lugar, la nueva ubicación sistemática del tema es significativa. Como hemos señalado ya, en el CEC la pena se insertaba en el marco del $5^{\circ}$ mandamiento («no matarás»), con lo cual se colocaba en la perspectiva restringida del bien jurídico lesionado. CDS, en cambio, lo hace en el contexto de la persona como fundamento y fin de la comunidad política (n. 384), y de la autoridad como encargada de respetar y promover valores y leyes que tutelan su dignidad (n. 397-398), enfocando el tema desde una perspectiva más amplia: la dignidad de todas las personas involucradas, no sólo la víctima o las personas afectadas, sino también el delincuente.

CDS introduce el tema de «infligir las penas» (n. 402) citando al CEC 2266: «Para tutelar el bien común, la autoridad pública legítima tiene el derecho y el deber de conminar penas proporcionadas a la gravedad de los delitos». Pero explicita a continuación qué entiende por «autoridad pública legítima»:

En el Estado de Derecho, el poder de infligir penas queda justamente confiado a la Magistratura: «Las Constituciones de los Estados modernos, al definir las relaciones que deben existir entre los poderes legislativo, ejecutivo y judicial, garantizan a este último la independencia necesaria en el ámbito de la ley».

Claramente se vincula la imposición de la pena a ciertas condiciones político-institucionales: la existencia de un Estado de Derecho (la cursiva es del texto), y una organización republicana del mismo, caracterizada por la división de poderes y la independencia de la Magistratura ${ }^{12}$. Se

\footnotetext{
12 En un nivel más específico, el n. 404 hace referencia a diversos principios que deben guiar la investigación y la actividad judicial: garantizar los derechos de todos; atenerse al principio de legalidad; exclusión absoluta de la tortura; rapidez de los procesos; justa indemnización por los errores judiciales. Esto muestra ulteriormente la tendencia del magisterio a considerar los problemas que acompañan la imposición y ejecución de la pena con un mayor realismo.
} 
supera así cierta carencia en la perspectiva ético-política del discurso anterior, que no percibía con suficiente claridad la relación entre la pena y la legitimidad y los límites del poder estatal, y por lo tanto, también con su modo de organización.

En cuanto a la potestad penal del Estado, dice el mismo n. 402:

El Estado tiene la doble tarea de reprimir los comportamientos lesivos de los derechos del hombre y de las reglas fundamentales de la convivencia civil, y remediar, mediante el sistema de las penas, el desorden causado por la acción delictiva.

Esta afirmación (que prolonga y completa CEC2 2266) es de especial importancia, porque constituye una profundización en la naturaleza del ius puniendi. La represión del delito constituye sólo el aspecto negativo de esta potestad, cuyo objetivo se extiende a la acción de «remediar (...) el desorden causado por la acción delictiva». Cabe pensar que el «desorden» aludido no es simplemente el de naturaleza metafísica o jurídica, ya que en tal caso sería extraño hablar de «remedian», en vez de, por ejemplo, «restablecen». Más bien la expresión parece referirse al daño inferido al tejido social, o sea, a las relaciones sociales concretas, por el hecho delictuoso. Y esto debe ser logrado también «a través del sistema de penas», que deben revestir entonces una finalidad restitutiva.

Así se sientan las bases para abordar de modo adecuado la naturaleza y la finalidad de la pena (n. 403). En cuanto a lo primero, CDS repite el CEC2: la pena tiene por fin la defensa de la sociedad (fin defensivo) y la corrección del delincuente (fin retributivo). Al concepto expiación puramente jurídica-exterior utilizado en $\mathrm{EV}$, y aquí indicado como «corrección», se agrega ahora nuevamente la idea de la expiación voluntaria de CEC 1 y 2.

Pero a esta consideración sobre la naturalez̧a de la pena, su "para qué» esencial sin el cual no sería siquiera una pena («la pena sirve para...»), se agrega en CDS una significativa afirmación sobre la «finalidad» de la pena:

La finalidad a la que tiende es doble: por una parte, favorecer la reinserción de las personas condenadas; por otra parte, promover una justicia reconciliadora, capaz de restaurar las relaciones de convivencia armoniosa rotas por el acto criminal (n. 403).

La idea de este número de CDS parece ser la siguiente. Una pena es esencialmente tal cuando es apta para defender a la sociedad del delito y 
corregir al culpable. Pero más allá de esta función próxima y esencial, que permite distinguir una pena de otros fenómenos exteriormente similares (ej., medidas de seguridad), su legitimidad, su carácter de pena justa en pleno sentido depende de su aptitud para procurar las dos finalidades enunciadas. Las mismas revelan una perspectiva netamente personalista y relacional. El ideal de la «justicia reconciliadora» es la recomposición del tejido social, incorporando al delincuente mismo, que debe restablecer sus vínculos con la comunidad para hacer posible su reinserción en ella ${ }^{13}$.

Tentativamente, se podría formular la siguiente conclusión. Para CDS la pena ya no tiene, como en el magisterio anterior, un fin principalmente retributivo, del cual se derivarían (de un modo que no se explica) en primer lugar, el fin defensivo y, por último (y eventualmente, porque depende de la libertad del delincuente), el fin medicinal, casi como un agregado. En el texto que analizamos, la pena es un instrumento para defender a la sociedad corrigiendo al delincuente: desaparece la idea de «compensar el desorden» (CEC), el fin defensivo y retributivo/expiativo son puestos en el mismo nivel como correlativos. Pero estos fines esenciales, que definen a la pena como tal, sólo pueden procurarse legítimamente a través de penas que sean en sí mismas aptas para hacer posible la reinserción del delincuente y la reconstitución de los vínculos sociales. Si la pena, por su contenido o modalidad, es inadecuada para cumplir estas dos finalidades, aunque siga siendo una pena desde el punto de vista jurídico-formal, pierde su justificación moral como acto de justicia, y se convierte en una pena injusta.

\section{La pena de muerte en CDS}

El n. 405, referido a la pena de muerte, es casi en su totalidad un entretejido de citas del CEC y EV. Resulta interesante notar que este número presenta lo que la técnica exegética suele denominar una «inclusión»: en este caso, el texto se abre y se cierra con una referencia a la evolución de la opinión pública en un sentido contrario a la pena capital. Citemos los dos textos:

La Iglesia ve como un signo de esperanza «la aversión cada vez más difundida en la opinión pública a la pena de muerte, incluso como instrumento de "legítima

13 En este sentido, la justicia reconciliadora asume el ideal de la justicia restitutiva, aunque existen entre ellas importantes diferencias. En especial, los defensores de este último concepto tienden a subestimar los desafíos que supone un auténtico proceso de enmienda, posiblemente como consecuencia de una antropología deficiente, cf. Skotnicki, 2006. 
defensa" social, al considerar las posibilidades con las que cuenta una sociedad moderna para reprimir eficazmente el crimen de modo que, neutralizando a quien lo ha cometido, no se le prive definitivamente de la posibilidad de redimirse $(\mathrm{EV} \mathrm{27,3)}(\ldots)$.

La creciente aversión de la opinión pública a la pena de muerte y las diversas disposiciones que tienden a su abolición o a la suspensión de su aplicación, constituyen manifestaciones visibles de una mayor sensibilidad moral.

Es inocultable que la actual aversión de la opinión pública hacia la pena capital, sobre la cual se hace tanto hincapié, está referida a la institución como tal, y apunta por lo tanto a su abolición. Da la impresión de que la opinión pública (aludida en modo crítico en otras materias) es aquí la vía elegida para expresar lo que la encíclica no se considera en condiciones de afirmar de modo directo: que si bien la enseñanza «tradicional» no excluye la pena de muerte en principio, el magisterio actual está completando su evolución en esa dirección. Insertando este virtual rechazo de la pena de muerte como tal, la admisión «en sordina» de su intrínseca injusticia, en el marco de la finalidad reconciliadora de la pena en general, CDS logra dar a su presentación de conjunto del tema penal un nivel de armonía y consistencia superior al de los textos precedentes.

\section{Fin retributivo y fin medicinal de la pena: ¿una alternativa?}

El itinerario que hemos recorrido nos permite constatar cómo, en pocos años, la doctrina católica de la pena ha experimentado cambios sustanciales. La irrupción en este tema, largamente diferida, de una nueva perspectiva teológica y antropológica, ha llevado a una ampliación del horizonte de reflexión, y a una reconfiguración de los elementos tradicionales en torno a la idea de la dignidad de toda persona humana, en su esencia metafísica y en su ser biográfico concreto.

El pensamiento cristiano siempre tuvo en cuenta junto a la función retributiva de la pena, su carácter medicinal, no sólo en la reflexión sino en la praxis. De hecho, la cárcel como pena en sí misma tiene su origen en la tradición monástica y está estrechamente ligada a la idea de conversión (Skotnicki, 2004; 2008: 73-127). Sin embargo, nunca logró dar plena consistencia a su doctrina, explicitando y llevando a sus últimas consecuencias los principios inspiradores de su disciplina penitencial. El fin retributivo adquirió, más en la práctica que en la teoría, un peso independiente, mientras que el fin medicinal, nunca rechazado por otro 
lado, quedó relegado a una eventualidad, enteramente dependiente de la libertad del reo, sin que se postulara ninguna relación intrínseca entre ambos aspectos. Se presentaba así una alternativa muy difícil de resolver: dar prioridad a la retribución acercaba peligrosamente la doctrina católica a las concepciones absolutas de la pena, pero enfatizar el fin medicinal parecía incompatible con una lógica auténticamente jurídica (la pena como respuesta al delito, y proporcionada a su gravedad). Y en esta tensión, es la dimensión retributiva la que tendía a prevalecer: después de todo, el delincuente expía su pena objetivamente cumpliendo la condena, aunque no cambie interiormente.

Pero esta última consideración es suficiente sólo en una perspectiva estrechamente jurídica. En ese nivel, se puede postular una cierta simetría entre el delito y la pena, la trasgresión a la ley y el castigo que restaura la soberanía de la ley. Pero considerando que el derecho penal tiene como primer fin la prevención del delito, es imperioso asumir una consideración más amplia, en que la conciencia de las personas constituye un factor esencial.

En efecto, sabemos que el efecto intimidatorio del derecho penal sobre la población en general (prevención general) es muy relativo (como lo demuestra la ineficacia del «endurecimiento» de las penas). Tampoco la aplicación de la pena produce, en las actuales condiciones, los efectos esperados (como lo atestiguan los altos porcentajes de reincidencia) ${ }^{14}$. La prevención estable, más que apoyarse en la amenaza de sanción, es sobre todo consecuencia de la autoridad de la norma, es decir, de su capacidad de proponer valores y modelos convincentes, y de suscitar en la conciencia de las personas una reacción favorable al mensaje que a contrariis propone la parte preceptiva de la norma.

El magisterio católico, al asumir el ideal de la justicia reconciliadora, va incluso más allá incluso de esta visión positiva de la prevención, porque postula no sólo la aceptación de los valores expresados por la ley, sino que apunta a la integración vital de las personas, incluyendo el delincuente, en la red de los vínculos comunitarios, comenzando por la familia y la comunidad local, devolviéndoles así un sentido de auténtica pertenencia y responsabilidad. En esta perspectiva, superadora del reductivo enfoque juridicista del pasado, queda en evidencia la insuperable asimetría entre el delito y la pena: esta última es por sí sola incapaz de reparar el desorden introducido por el delito.

\footnotetext{
14 En numerosos países de la Unión Europea, así como en Canadá y los Estados Unidos, la tasa de reincidencia penitenciaria en un lapso de tres años supera largamente el 40 \%, cf. Capdevilla Capdevilla \& Ferrer Puig, 2009: 33-34.
} 
Pero precisamente la aceptación de dicha asimetría nos señala el camino a seguir. Nuestra concepción católica de la pena (como la del sistema penal en general) debe ser purificada del mito de la retribución justa, en el sentido de que pueda medirse matemáticamente conforme a la culpabilidad, expresar la gravedad del mal cometido y compensarlo (mito que posiblemente esté detrás del éxito de la pena de prisión, fácilmente cuantificable). Además, en este esquema, la mirada de la justicia queda focalizada en el pasado, identifica al delincuente con el hecho cometido, lo "clava" al mismo, no le brinda la oportunidad de liberarse de los condicionamientos negativos, y lo convierte en mero portador de la pena, desconociéndolo como persona.

Para trascender esta lógica de la retribución no basta apelar al buen sentimiento de la autoridad de aplicación. La sanción aplicada debe ser intrínsecamente diferente del mal, debe dejar de concebirse como respuesta especular al mal cometido. Debe pensarse una respuesta al delito que constituya un recorrido o proceso potencialmente significativo para el autor. no un mal, aunque sí una negación del delito, una respuesta que se oponga a la voluntad criminal en sus efectos, a la posibilidad de su reiteración, y que importe una declaración pública de su ilicitud (Eusebi, 2007a: 107-113) ${ }^{15}$.

\section{La retribución medicinal}

Es preciso por lo tanto, devolver al fin medicinal su verdadera jerarquía en el contexto de la reflexión sobre la pena, jerarquía que expresaba Santo Tomás al sostener que: «Las penas de la vida presente más bien («magis») son medicinales que retributivas; porque la retribución está reservada al juicio divino, que se hará, según la verdad (Rom 2,2), contra los pecadores» (Summa Theologiae, II-II, q.66, a.6, ad. 2). Esta afirmación debe ser interpretada en el sentido de una vinculación intrínseca del fin medicinal con la pena, es decir, que ésta debe ser de tal naturaleza que facilite y estimule la conversión, la enmienda y la expiación.

(Debemos cuidarnos) de creer que S. Tomás, al hablar del fin medicinal, se está refiriendo solamente al hecho obvio y reconocido de que toda pena, por el solo hecho de serlo, produce algún efecto medicinal, v.gr., temor de cometer delitos. Por supuesto que el Aquinate tiene en cuenta y menciona estos efectos. Pero la importancia del carácter medicinal que él les asigna a

\footnotetext{
15 Es claro que la efectiva superación de la lógica puramente retributiva presupone una reforma del conjunto del sistema criminal, en especial, de las agencias judiciales y ejecutivas, tema que aquí no es posible abordar. Para una idea general de la problemática, remito a Zaffaroni, 1989: 121-149.
} 
las penas humanas estriba, fundamentalmente, en la incidencia que tal carácter puede tener en la determinación de la pena (Codesido \& Martini, 2005: 46).

De un modo consistente con lo anterior, S. Tomás reconoce que el fin medicinal puede influir en la medida de la pena ya que, si bien las penas que Dios aplicará en la vida futura responderán a la gravedad de la culpa, las penas de la presente vida deben tener en cuenta también otros criterios (De Malo, q.2, a.10, ad 4). Se llega así a una importante conclusión:

La función medicinal, entonces, se ha transformado en una medida de la justicia humana. No en la única ni en la primera, ya que, ante todo, debe siempre afirmarse que no puede haber pena sin culpa, pero luego, en la adecuación de la pena a la culpa, en el modo mismo de determinar la igualdad propia de la justicia, el efecto medicinal interviene como limite y medida porque, por un lado, exige analizar la utilidad de la pena para comprobar si es apta para causar aquél efecto (S.Th., II-II, 99, 4) y, por otro, lleva a descartar penas que, si bien en el plano de un puro análisis teórico moral y jurídico pueden aparecer como justas, sin embargo no lo son en realidad ni bien se atiende a esta dimensión de la pena como medicina (Codesido \& Martini, 2005: 51, cursiva nuestra).

De lo dicho se sigue que el fin retributivo y el fin medicinal no deben considerarse como fines separados y jerarquizados entre sí. La función de enmienda no es extrínseca a la pena retributiva. Si lo fuera, cualquier pena, incluso una cruel o desproporcionada, podría producir el efecto de llevar al delincuente a la conversión. El carácter medicinal no sería en absoluto criterio para juzgar la legitimidad de la pena. La diferencia entre la justicia escatológica y la justicia terrenal se perdería irremisiblemente. Por lo tanto, el fin medicinal tiene que estar vinculado intrínsecamente con la pena, es decir, que la pena debe ser de tal naturaleza que facilite y estimule la conversión, la enmienda y la expiación ${ }^{16}$.

\section{Justicia reconciliadora y estrategias sancionadoras}

La idea de la retribución medicinal debe plasmarse en modalidades sancionadoras dirigidas a la responsabilización, la composición de conflictos y la reparación, o a recorridos de rehabilitación no carcelarios:

\footnotetext{
16 El ejemplo más claro de una pena concebida como medicinal es la pena de prisión; cf. Skotnicki, 2004: 793-816; 2008: 115-127.
} 
sanciones pecuniarias, intervenciones patrimoniales, interdicciones, mediación penal, etc. (Eusebi, 2007b). La pena de prisión debería ser desplazada del lugar central que ahora posee, quedando como extrema ratio, para los casos de peligro de reiteración de delitos graves, a favor de estrategias alternativas que permitan una valorización activa del bien ofendido, y sean simbólicamente más significativas que el automatismo de la mera retribución.

En el período que hemos analizado en este trabajo, la Iglesia católica se ha aventurado por el difícil y fecundo camino de la justicia reconciliadora. Y si a lo largo de la historia siempre se ha mostrado sensible al drama de los encarcelados, hoy por primera vez comienza a someter a crítica el sistema penal en sí mismo. Sin duda, este es el fruto de haber escuchado, con una nueva profundidad, aquellas palabras del Señor que son para nosotros, Iglesia peregrina, al mismo tiempo aliento y exigencia: «estuve preso, y me visitasteis».

\section{REFERENCIAS}

-Blázquez, N. (1996). La pena de muerte. En R. Lucas Lucas (Ed.), Comentario interdisciplinar a la «Evangelium Vitae» (págs. 403-418). Madrid: Biblioteca de Autores Cristianos.

-Bondolfi, A. (1990). Ética política. En T. Goffi \& G. Piana (Eds.), Corso di Morale (Vol. IV. Koinonia. Etica della vita sociale) (págs. 85-348). Brescia: Queriniana.

-Capdevilla Capdevilla, M. \& Ferrer Puig, M. (2009). Tasa de reincidencia penitenciaria 2008 (Àmbit social i Criminològic. Centre d'Estudis Jurídics i Formació Especialitzada. Generalitat de Catalunya. Departament de Justícia). Recuperado el 12 de abril de 2012: http://www20.gencat.cat/docs/Justicia/Documents/ARXIUS/SC-1-07609 cas.pdf.

-Carlotti, P. (2007). La pena di morte. L'attuale sviluppo magisteriale. En AAVV., Chi è senza peccato scagli la prima pietra (págs. 27-54). Roma: PUG.

-Codesido, E. \& Martini, S. de (2005). El concepto de pena y sus implicancias jurídicas en S. Tomás de Aquino. Buenos Aires: El Derecho.

-Conferencia de los Obispos Católicos de los Estados Unidos (1990). Responsibility, Rehabilitation, and Restoration: A Catholic Perspective on Crime and Criminal Justice, 15 Noviembre.

-D’Agostino, F. (1992). Justicia penal. En F. Compagnoni, G. Piana, S. Privitera \& M. Vidal (Eds.), Nuevo Diccionario de Teología Moral (págs. 994-1004). Madrid: Paulinas.

-Eusebi, L. (1998). Le istanze del pensiero cristiano e il dibattito sulla riforma del sistema penale nello Stato laico. En A. Acerbi \& L. Eusebi (Eds.), Colpa 
e pena? La teologia di fronte alla questione criminale (págs. 207-250). Milano: Vita e Pensiero.

-Eusebi, L. (2007a). Devianza e prevenzione. En Encuentro Internacional de Derecho Penal (págs. 107-113). Buenos Aires: Universidad Católica Argentina / A-Z Editora.

-Eusebi, L. (2007b). Modelli di prevenzione dei reati e riforma del sistema penale sanzionatorio (IV Assemblea Nazionale del Volontariato Giustizia, Roma 17-19 maggio). Recuperado el 10 de abril de 2012: http://www.ristretti.it/commenti/2007/giugno/cnvg_2007.pdf.

-Fabris, R. (2003). La giustizia che salva. Rivista di Teologia Morale (138), 195-199.

-Foucault, M. (2002). Vigilar y Castigar. Nacimiento de la prisión. Buenos Aires: Siglo XXI.

-Highton, E., Álvarez, G., \& Gregorio, C. (1998). Resolución alternativa de disputas y sistema penal. La mediación penal y los programas víctima-victimario. Buenos Aires: Adhoc.

-Koch, K. (1972). Gibt es ein Vergeltungsdogma im Alten Testament? En K. Koch, Um das prinzip der Vergeltung in Religion und Recht des Alten testaments, Darmstadt: Wissenschaftliche Buchgesellschaft.

-Lattuada, A. (1998). La giusta reazione giuridico-sociale al fenomeno del crimine. Il contributo della teologia morale. En A. Acerbi \& L. Eusebi (Eds.), Colpa e pena? La teologia di fronte alla questione criminale (págs. 179-206), Milano: Vita e Pensiero.

-León-Dufour, X. (1985). Vocabulario de Teología Bíblica. Barcelona: Herder.

-McCormick, P. (2000). Just Punishment and America's Prison Experiment, Theological Studies 61, 508-532.

-Pío XII (1953). Nous Croyons. Alocución al VI Congreso Internacional de Derecho Penal, L'Osservatore Romano, 3 de octubre [AAS 45 (1953)].

-Pío XII (1955). Accogliete illustri. Función natural de la pena jurídica: redimir al culpable por la penitencia. Discurso al VI Congreso de Estudios de la Unión de los Juristas Católicos Italianos, L'Osservatore Romano, 5 de diciembre [AAS 47 (1955)].

-Skotnicki, A. (2004). Foundations once destroyed: the Catholic Church and Criminal Justice. Theological Studies 65, 792-816.

-Skotnicki, A. (2006). How is Justice restored? Studies in Christian Ethics, 19 (2), 187-204.

-Skotnicki, A. (2008). Criminal Justice and the Catholic Church. New York: Sheed \& Ward.

-Thiéfry, M. (1961). La justice doit-elle cesser de «juger» et de punir? Nouvelle Revue Théologique 73, 466-482.

-Yacobucci, G. (2000): La deslegitimación de la potestad penal. Buenos Aires: Ábaco.

-Zaffaroni, E. (1989). En busca de las penas perdidas. Deslegitimación y dogmática jurídico-penal. Buenos Aires: EDIAR.

-Wiesnet, E. (1987). Pena e retribuzione: la riconciliazione tradita. Sul rapporto fra cristianesimo e pena. Milano: Giuffrè. 
Sumario: 1. La pena en el Magisterio de Pío XII; 2. Razones de un cambio; 3. La pena en el CEC1 (1992); 4. CEC1 y pena de muerte; 5. Pena en general y pena de muerte en EV; 6. La pena en CEC2; 7. CEC2 y la pena de muerte; 8. La pena y el jubileo en las cárceles (2000): la justicia y el perdón; 9. La pena en el CDS; 10. La pena de muerte en CDS; 11. Fin retributivo y fin medicinal de la pena: ¿Una alternativa?; 12. La retribución medicinal; 13. Justicia reconciliadora y estrategias sancionadoras. Referencias. 